\title{
Pemberdayaan Divisi Pembinaan MKEK melalui Kerja Proaktif dan Pemberian Sanksi berupa Pembinaan
}

\author{
Frans Santosa ${ }^{\mathrm{I}, 2^{*}}$, Pukovisa Prawiroharjo ${ }^{\mathrm{I}, 3^{*}}$ \\ ${ }^{\mathrm{I}}$ Majelis Kehormatan Etik Kedokteran Pengurus Besar Ikatan Dokter Indonesia \\ ${ }^{2}$ Fakultas Kedokteran Universitas Pembangunan Nasional Veteran Jakarta \\ 3Departemen Neurologi, Fakultas Kedokteran Universitas Indonesia/Rumah Sakit Cipto Mangunkusumo, Jakarta \\ * Penulis-penulis ini berkontribusi seimbang (Theseauthars contributed equally)
}

\section{Kata Kunci \\ etik, MKEK, pembinaan \\ Korespondensi \\ pukovisa@ui.ac.id \\ Publikasi \\ (C) $2018 \mathrm{JEKI} /$ ilmiah.id \\ DOI \\ I0.26880/jeki.v2i3.22}

Tanggal masuk: 2 Juli 2018

Tanggal ditelaah: ${ }_{4}$ Oktober 2018

Tanggal diterima: 12 Oktober 2018

Tanggal publikasi: 24 Oktober 2018

\begin{abstract}
Abstrak Profesi dokter yang luhur dikendalikan oleh suatu sistem pascakampus berupa pembinaan etika perilaku dan profesionalisme. Salah satu organ yang menjadi pejuang lini terdepan dalam penegakkan etika kedokteran dalam struktur organisasi profesi Ikatan Dokter Indonesia (IDI) adalah Majelis Kehormatan Etik Kedokteran (MKEK). Dalam menjalankan tujuan utamanya sesuaiPedoman Organisasi dan Tatalaksana Kerja (Ortala) MKEK 2008 dan AD/ART IDI, MKEK membentuk dua divisi yaitu Divisi Pembinaan dan Divisi Kemahkamahan. Seiring dengan rencana pembaharuan Ortala, kami memandang perlunya penguatan peran Divisi Pembinaan antara lain dengan menjabarkan Divisi Pembinaan dapat proaktif dalam bekerja (tidak harus menunggu aduan dahulu) dan memberi kewenangan tambahan bagi Divisi Pembinaan untuk dapat memberi sanksi sebatas pembinaan perilaku pada pelanggaran etik ringan, sehingga memudahkan MKEK mencapai tujuan hakikinya yaitu menjaga dan meningkatkan etika perilaku dan profesionalisme seluruh dokter Indonesia.
\end{abstract}

Abstract Doctor's profession is maintained by a postgraduate control system of ethical behavior and professionalism. One of the front-line entities in enforcement of medical ethics inside doctors' professional organization of Indonesian Doctors Association (IDI) is the Medical Ethics Council of Honors (MKEK). In carrying out its main objectives in accordance with MKEK 2008 Organization and Management Guidelines (Ortala) and IDI Statutes / Articles of Association, MKEK established two divisions namely the Guidance Division and the Judicial Division. Along with renewal plan of Ortala, we saw the need to strengthen the role of Guidance Division, among which by explicitly mentioning the Guidance Division to be proactive (not having to wait for complaints beforehand) and giving additional authority to Guidance Division to be able to impose sanctions limited to guidance on minor ethical violations, thus making it easier for MKEK to achieve its essential objectives, which is to maintain and enhance the ethics on behavior and professionalism of all Indonesian doctors.

\section{PENDAHULUAN}

Profesi dokter masih merupakan profesi yang cukup terhormat di mata masyarakat. Salah satu fondasi mengapa profesi dokter dihormati ialah adanya sistem kendali pascapendidikan berupa pembinaan etika perilaku dan profesionalisme serta pemutakhiran ilmu. Saat mengenyam pendidikan dokter, para calon dokter digembleng dan dibentuk sikap dan perilakunya oleh para dosen dan sistem yang berlaku di fakultas kedokteran dan rumah sakit pendidikan. Setelah lulus dan mendapatkan ijazah pengakuan sebagai dokter dan jenjang pendidikan setelahnya, maka pelestarian, penjagaan, dan peningkatan karakter perilaku 
dan profesionalisme beralih tanggung jawab dari kampus ke organisasi profesi dan sistem di fasilitas pelayanan kesehatan (fasyankes) atau tempat bertugas. Dalam sebagian kasus, sistem di fasyankes cukup efektif untuk memastikan etika perilaku dokter terjaga dengan baik. Namun, sebagian lainnya terkendala oleh berbagai faktor, misalnya konflik kepentingan antara status seorang dokter sebagai pemegang kekuasaan di RS, baik sebagai pemilik, komisaris, atau direksi, dengan perannya sebagai staf medis fungsional. Kendala lain ialah jarangnya suatu keahlian di suatu daerah sehingga justru figur dokter spesialis/subspesialis pada daerah tersebut lebih tampak memegang kendali dibandingkan penegakkan aturan di RS.

Keterbatasan fasyankes melakukan kontrol atas perilaku etik seluruh staf mediknya membuat harapan masyarakat bertumpu pada efektivitas organisasi profesi untuk menegakkan etika kedokteran dengan baik dan memastikan masyarakat berjumpa dengan dokter yang indah perilakunya, di samping pengetahuan dan keterampilannya yang mumpuni. Salah satu organ yang menjadi pejuang lini terdepan dalam penegakan etika kedokteran dalam struktur organisasi profesi Ikatan Dokter Indonesia (IDI) adalah Majelis Kehormatan Etik Kedokteran (MKEK). Organ ini kini juga diberi keleluasaan berkoordinasi dengan jajaran Dewan Etik yang dibentuk di setiap Perhimpunan Dokter Spesialis atau Pelayanan Primer (PDSp/PDPP).

Dalam menjalankan tujuan utamanya untuk melakukan kontrol atas perilaku etik, sesuai Pedoman Organisasi dan Tatalaksana Kerja (Ortala) MKEK $2008^{1}$ dan AD/ART IDI, ${ }^{2}$ MKEK membentuk dua divisi, yaitu Divisi Pembinaan dan Divisi Kemahkamahan. Pembagian tugas yang tertera jelas di Ortala MKEK antara kedua divisi tersebut secara garis besarnya ialah bahwa Divisi Pembinaan melakukan tindak lanjut sanksi yang bersifat pembinaan perilaku, yang telah digariskan melalui persidangan kemahkamahan MKEK yang diselenggarakan Majelis Pemeriksa Divisi Kemahkamahan. Divisi Pembinaan dapat pula membuat laporan temuan dari informasi yang mereka dapatkan untuk kemudian menjadi masukan sah atas diselenggarakannya kemahkamahan MKEK. Sementara Divisi Kemahkamahan MKEK menyelenggarakan persidangan yang baik untuk memutuskan apakah pada suatu kasus terjadi pelanggaran etik atau tidak, serta memutuskan sanksi yang bijaksana pada aduan yang dialamatkan kepada MKEK sesuai yurisdiksinya. ${ }^{1}$

Secara umum, Ortala MKEK 2008 dinilai telah baik dalam melakukan pembagian tugas antara Divisi Pembinaan dan Divisi Kemahkamahan MKEK, dan memungkinkan masing-masing Divisi bekerja sesuai tugas pokok dan fungsinya. Namun, dengan melihat perkembangan terkini tampak bahwa tantangan untuk selalu dapat berperilaku etis bagi seorang dokter semakin berat. Hal ini disebabkan oleh adanya persaingan antar RS dan antar dokter, sistem jaminan kesehatan, efek signifikan dari perkembangan teknologi dan media sosial, ${ }^{3}$ masifnya informasi di antara dokter dan terkait informasi kesehatan di masyarakat, dan perkembangan-perkembangan lainnya. Hal ini perlu direspon dengan langkahlangkah yang signifikan untuk optimalisasi pemberdayaan organ di dalam organisasi profesi. Oleh karenanya melalui artikel ini, kami mengajukan usulan perubahan Ortala agar Divisi Pembinaan MKEK dapat lebih berdaya dan efektif dalam menjalankan tugasnya dalam menjaga dan meningkatkan etika perilaku dan profesionalisme dokter Indonesia.

\section{HASIL DAN PEMBAHASAN}

\section{Menjabarkan dengan Jelas bahwa Divisi Pembinaan Dapat Proaktif dalam Bekerja}

Berbeda dengan Divisi Kemahkamahan yang dalam bekerja perlu masukan terlebih dahulu dan biasanya berupa aduan dugaan pelanggaran etik dari masyarakat, Divisi Pembinaan sebaiknya tidak dibatasi oleh aturan bahwa harus ada aduan terlebih dahulu baru bergerak. Meskipun di Ortala MKEK 2008 hal ini tidak jelas diterangkan untuk Divisi Pembinaan MKEK (berbeda dengan Divisi Kemahkamahan), namun juga tidak dijabarkan jelas bahwa Divisi Pembinaan dapat bekerja secara proaktif menemui kasus bahkan jika perlu dapat inspeksi mendadak turun 
langsung ke lapangan untuk mengklarifikasi dan mengonfirmasi adakah pelanggaran etika kedokteran di tempat tersebut. ${ }^{1}$

Bekerja secara proaktif yang dimaksud meliputi pencarian, penelaahan, klarifikasi, serta mengadakan sidang pembinaan terhadap suatu informasi dugaan pelanggaran etik secara aktif. Penelaahan dapat dilakukan dengan membandingkan temuan informasi dengan KODEKI, fatwa etik terkait, atau kajian etik yang spesifik mengulas hal tersebut. Misalnya saja penelaahan terhadap informasi yang berpotensi menjadi aktivitas mengiklankan diri, perlu untuk ditelaah tidak hanya dengan subjektivitas pengurus MKEK tetapi harus ditelaah juga dari kajian khusus tentang batasan dokter beriklan. ${ }^{4}$ Atau penelaahan informasi terkait dugaan pelanggaran etik yang melibatkan informasi di media sosial, pengurus melakukan penelaahan menggunakan kajian khusus tentang etika dokter di media sosial. ${ }^{3}$

Oleh karenanya satu usulan dari kami dalam perubahan Ortala MKEK mendatang ialah menjabarkan jelas bahwa Divisi Pembinaan dapat proaktif dalam bekerja dan terjun langsung. Wewenang yang mirip memang dapat beririsan dengan tim BHP2A IDI, ${ }^{2}$ tetapi mempertimbangkan bahwa potensi temuan di lapangan dan informasi sehari-hari sedemikian banyak, maka tidak keliru jika wewenang tersebut juga dimiliki oleh Divisi Pembinaan MKEK dan Dewan Etik PDSp/PDPP. Sebagai mekanisme mediasi jika suatu informasi atau kejadian lapangan ditindaklanjuti bersamaan oleh BHP2A IDI dan Divisi Pembinaan MKEK, maka Ketua MKEK dan ketua IDI setingkat dapat membuat tim gabungan antara BHP2A IDI dan Divisi Pembinaan MKEK untuk menindaklanjuti bersama-sama. Demikian pula jika hal tersebut terjadi di kepengurusan PDSp/ PDPP.

\section{Memberi Kewenangan Divisi Pembinaan Memberi Sanksi Sebatas Pembinaan Perilaku pada Pe=langgaran Etik Ringan}

Merujuk pada Ortala MKEK 2008, penetapan sanksi seluruhnya menjadi domain Divisi Kemahkamahan MKEK melalui sidang kemahkamahan dan ditentukan oleh Majelis
Pemeriksa yang ditugaskan untuk setiap aduan yang ada dan dianalisis sesuai dengan nilainilai luhur profesi kedokteran yang dijabarkan pada Kode Etik Kedokteran Indonesia. ${ }^{1} \mathrm{Hal}$ ini berlaku untuk segala jenis sanksi, mulai dari yang sangat ringan, seperti peringatan lisan, hingga sanksi berat berupa pemecatan keanggotaan. Masalah berpotensi muncul karena tata prosedur sidang kemahkamahan sangat kompleks dan panjang, membutuhkan banyak sumber daya waktu dan manusia, dan umumnya memakan waktu hingga 90 hari kerja (3 bulan lebih). Sehingga terkadang untuk kesalahan yang tampak ringan dari penelaahan awal , dapat berpotensi tidak ditindaklanjuti lebih jauh dan dihentikan kasusnya begitu saja tanpa ada sanksi apapun juga. Hal ini tentu tidak diharapkan oleh masyarakat dari peranan MKEK dan bagaimana MKEK menjawab harapan masyarakat kepadanya.

Oleh karena itu, terobosan perlu dilakukan untuk menyederhanakan penanganan aduan yang tampak ringan dalam penelaahan. Mempertimbangkan hal tersebut, maka kami mengusulkan adanya pemberian kewenangan tambahan kepada Divisi Pembinaan MKEK agar dapat membuat sidang pembinaan sebagai tatalaksana aduan/informasi dugaan pelanggaran etik. Dalam sidang pembinaan ini, jika dalam penelaahan tampak hanyalah masalah pelanggaran etik ringan, maka Divisi Pembinaan berwenang untuk memberikan sanksi sebatas pembinaan perilaku. ${ }^{5}$

Terkait bentuk sanksi yang bersifat pembinaan perlu dijabarkan lebih jelas secara operasional dalam perubahan Ortala MKEK. Sehubungan dengan rancangan sanksi tiga kategori (kategori 1: pembinaan perilaku, kategori 2: penginsafan tanpa pemecatan, dan kategori 3: penginsafan dengan pemecatan sementara), ${ }^{6}$ harus diperjelas bahwa batasan sanksi yang menjadi wewenang sidang Divisi Pembinaan MKEK hanyalah sanksi kategori 1, dan tidak termasuk pemecatan keanggotaan sebagaimana yang tercantum dalam Ortala 2008 yang terdahulu. ${ }^{1}$

Putusan sidang pembinaan ini sebaiknya lebih bersifat tertutup dibandingkan sidang kemahkamahan karena tujuannya adalah 
membina perilaku dan bukan penginsafan (publikasi ke pihak luar merupakan salah satu elemen penginsafan). Pelanggaran etik yang ringan perlu dijaga dari berbagai pihak untuk tidak dibesar-besarkan dan sanksi yang dikenakan murni merupakan pembinaan perilaku. Sifat putusan ini dapat terbuka jika hal ini justru yang diinginkan oleh dokter yang diberikan sanksi tersebut. Pengecuali lain ialah jika sanksi yang dijatuhkan mengikat untuk dibuka baik sebagian atau pun utuh kepada beberapa pihak, atau pelanggaran etika tersebut terkait penyebaran berita bohong (hoax) yang masif terkait info kesehatan, meresahkan masyarakat, atau merugikan marwah profesi kedokteran secara nyata sehingga diperlukan klarifikasi kepada publik. ${ }^{7}$

Untuk menghindarkan potensi miskomunikasi dan meningkatkan sinergi antardivisi di MKEK, diusulkan pula bahwa sidang pembinaan tersebut harus dihadiri minimal satu orang anggota Divisi Kemahkamahan MKEK setempat.

\section{KESIMPULAN}

Dalam rencana mengubah Pedoman Organisasi dan Tatalaksana Kerja MKEK, diperlukan penguatan peran Divisi Pembinaan, antara lain dengan menjabarkan Divisi Pembinaan dapat proaktif dalam bekerja (tidak harus menunggu aduan dahulu) dan memberi kewenangan tambahan bagi Divisi Pembinaan untuk dapat memberi sanksi sebatas pembinaan perilaku pada pelanggaran etik ringan. Dua usulan ini diharapkan dapat memudahkan MKEK mencapai tujuan hakikinya, yaitu menjaga dan meningkatkan etika perilaku dan profesionalisme seluruh dokter Indonesia.

\section{KONFLIK KEPENTINGAN}

Tidak ada konflik kepentingan.

\section{REFERENSI}

1. Purwadianto A, editor. Pedoman organisasi dan tata laksana kerja Majelis Kehormatan Etik Kedokteran. Jakarta: Majelis
Kehormatan Etika Kedokteran Ikatan Dokter Indonesia; 2008.

2. Muktamar Ikatan Dokter Indonesia XXIX. Anggaran dasar dan anggaran rumah tangga Ikatan Dokter Indonesia. 2015.

3. Prawiroharjo P, Librianty N. Tinjauan etika penggunaan media sosial oleh dokter. J Etik Ked Ind. 2017 Oct 11;1(1):31. https://doi. org/10.26880/jeki.v1i1.7.

4. Prawiroharjo P, Meilia PDI. Dokter beriklan: Sebuah tinjauan menurut Kode Etik Kedokteran Indonesia (KODEKI) tahun 2012. J Etik Ked Ind. 2017 Oct 11;1(1):13. https://doi. org/10.26880/jeki.v1i1.4.

5. Rozaliyani A, Meilia PDI, Librianty N. Prinsip penetapan sanksi bagi pelanggaran etik kedokteran. J Etik Ked Ind. 2018 Mar 19;2(1):19. https://doi.org/10.26880/jeki.v2i1.11.

6. Prawiroharjo P, Purwadianto A. Sistem akumulasi sanksi: Usulan perubahan kategorisasi dan akumulasi penetapan sanksi untuk pelanggaran etik kedokteran. Belum diterbitkan.

7. Prawiroharjo P, Santosa F, Lefrandt R, Sidipratomo P, Purwadianto A. Dapatkah keputusan kemahkamahan etik Majelis Kehormatan Etik Kedokteran bersifat terbuka? J Etik Ked Ind. 2018 Jun 12;2(2):45. https:// doi.org/10.26880/jeki.v2i2.15. 